\title{
用差示扫描量热计对低水含量 蛋白质热变性的研究
}

——热变性前新峰”的证实

傅 亚 珍

(中国科学院生物物理研究所, 北京)

摘 要

本文继发现水合牛血清白蛋白存在低温区吸热峰之后,进一步测定了11个厂家 生产的 7 种高纯低水含量蛋白质的 DSC 加热扫描曲线。证实在热变性峰之前的低温 区无一例外都有一个明显可辩的小吸热峰, 我们将它命佲为“热变性前新峰”(Prethermodenaturation new peak). 结果表明“热变性前新峰”的出现是低水含量蛋白质的 共性. 对新峰规律和机制的研究将有助于人们深入理解蛋白质的变性过程、肽链折 叠途径、分子的缔合、解缔合及其溶剂效应.

生命系统正常结构和功能的维持, 离不开水的作用. 作为生命物质基础之一的蛋白质, 没 有水便没有它们完整的结构和生物功能. 这就是蛋白质和水的相互作用的研究所以成为近几 十年来蛋白质化学的重要研究课题的原因所在. 然而, 由于所研究问题的复杂程度,致使人们. 对蛋白质和水相互作用的细节至今仍了解甚少. 目前, 国内外已使用各种技术（等温吸附技 术 $^{[1-2]}$ 、红外光谱技术 ${ }^{[3]}$ 、核磁共振技术 ${ }^{[4-7]}$ 、拉曼光谱技术 ${ }^{[8-9]}$ 、介电弛豫测量技术 ${ }^{[0-12]}$ 、量热技 术 ${ }^{[13-191)}$ 等）广泛地研究了蛋白质的水合过程以及水合对蛋白质的构象、稳定性及其功能的影 响.

量热技术可以直接测定蛋白质与水相互作用的热力学特性. 我们曾用差示扫描量热计 $\left(\mathrm{P} / \mathrm{E} \mathrm{DSC}_{-2}\right)$ 研究了水合对牛血清白蛋白热稳定性的影响, 并首次发现在变性峰前于一定水 合范围内存在一个小的吸热峰 ${ }^{[18]}$. 指出了在一定水含量下,该峰的出现“似乎是血清白蛋白的 共性”。后来,又证明样品中脂肪酸的含量并不影响该峰的出现 ${ }^{[199}$.

本文对 11 个厂家出品的 7 种具一定低水合值的高纯蛋白质用 $\mathrm{DSC}_{-2}$ 进行量 热学测量. 发现所有样品在热变性前的低温区无一例外都有一个明显可辨的小吸热峰, 我们将它命名为 “热变性前新峰”（pre-thermodenature new peak). 结果表明“热变性前新峰”的出现是低水含 量蛋白质的共性。 


\section{一、材料和 方 法}

1. 实验材料本文所使用的实验材料为 11 种高纯蛋白质样品, 系 11 个厂家出品的 7 种蛋白质(见表 1 )。

表 1 实验材 料

\begin{tabular}{|c|c|c|c|c|}
\hline 序 号 & 样品名称 & 厂 家 & 规 格 & 产品号 \\
\hline 1 & 牛血清白蛋白 & Sigma & 实质上无脂肪酸 & Lot $90 \mathrm{~F}-9315$ \\
\hline 2 & 牛血清白蛋白 & Sigma & 实质上无球蛋白 & Lot $61 \mathrm{~F}-9335$ \\
\hline 3 & 牛血清白蛋白 & Serva & 纯度 $>99 \%$ & No 11920 \\
\hline 4 & 牛血清白蛋白 & Fluka AG & 纯度 $>99 \%$ & No 05470 \\
\hline 5 & 肌 红 蟫 白 & Sigma & 无盐、结晶、冻干 & Lot $59 \mathrm{C}-7480$ \\
\hline 6 & 胰凝乳蛋白酶 & Fluka AG & 纯 & No 24005 \\
\hline 7 & 刀豆球蛋白 A & $\mathrm{BDH}$ & 无盐、冻千粉末 & No 44203 \\
\hline 8 & 溶 菌 酶 & 中国东风试剂厂 & 二次结晶、冻干粉末 & $81-279$ \\
\hline 9 & 溶 菌 酶 & Sigma & 三次结晶、冻干粉末 & Lot $81 \mathrm{~F}-8200$ \\
\hline 10 & 核糖核酸酶 & Boehringer & 40 单位 $/ \mathrm{mg}$. 㑈干粉末 & No 109126 \\
\hline 11 & 胶 原 蛋 白 & Calbiochem-Behring Corp & 仅供实验空用 & Lot 901627 \\
\hline
\end{tabular}

2. 样品制备 所用样品中球蛋白呈粉末状, 胶原蛋白呈块状. 粉末状样品需先用自制 压片器制成直径 $3.5 \mathrm{~mm}$ 、厚度 $2.0 \mathrm{~mm}$ 的圆片. 称重后将样品分别装进挥发型铝制样品盘 $(\mathrm{P} /$ $\mathrm{E}$ 公司产品) 内, 并置于盛有 $\mathrm{NaBr}$ 饱和盐溶液的密封干燥器中, 在室温下放置 $5 \mathrm{~d}$ 以获取一定 水含量的样品，然后将样品盘密封，在室温下放置 $1 \mathrm{~d}$ 后待测. 样品干重范 围 为 $7.97 \mathrm{mg一}$ $9.31 \mathrm{mg}$. 胶原蛋白样品的制备除了不需压片外其余步骤与球蛋白的制样方法相同.

3. 测试方法 用 $\mathrm{P} / \mathrm{E} \mathrm{DSC}-2$ 型差示扫描量热计记录各样品的热谱图.用内冷却器 II 使 样品架外的块体环境恒定于低温. 扫描起始温度为 $280^{\circ} \mathrm{K}$, 完成变性过程并获取较好基线时 的温度为扫描终止温度. 升温速率 $5^{\circ} \mathrm{K} / \mathrm{min}$. 仪器灵敏度 $1 \mathrm{mcal} / \mathrm{s}$ - 满刻度. 图速 $10 \mathrm{~mm} /$ min. 参考盘为空盘. 用高纯铟 $(\mathrm{P} / \mathrm{E}$ 公司提供)及玻璃重蒸水做仪器的温度校准. 用高纯铟 做仪器的能量校准.

本实验选取热谱图中变性前新峰的峰顶位温度作为新峰的峰温 $T_{P D}$. 用 Tektronix 31 型 计算机检出变性前新峰的焓变值 $\Delta H_{P D}$. 同样选取变性峰的峰顶位温度作为变性温度 $T_{D}$.

实验后将样品盘的盖子扎数个针孔，置于 $105^{\circ} \mathrm{C}-110^{\circ} \mathrm{C}$ 的恒温千燥箱内, 干燥 $48 \mathrm{~h}$ 用干 蜗前后样品盘重量之差测其样品总失水量,并计算出样品干重，以水合值 $\mathrm{R}$ (克水/克干蛋白) 表示样品的含水量.

\section{二、结果和讨论}

图 1 为 11 种高纯蛋白质样品自 $280^{\circ} \mathrm{K}$ 开始至热变性完成的 DSC 加热扫描曲线图. 图中 各曲线的序号所代表的蛋白质样品名称见表 1 及表 2 .图 2 为前后两次连续测试样品的 DSC加 热扫描曲线. 其中曲线 1 为测试前空样品盘的扫描基线,曲线 2 为测试样品的 DSC 曲线, 曲线 3 为对样品扫描后立即快速冷却至 $280^{\circ} \mathrm{K}$ 以后再进行第二次扫描的曲线。表 2 列出所测样 品的状态参数及由 DSC 所测出的热力学参数。 
从图 1 的 DSC 加热扫描曲线上，我们可以清楚地看到 11 种蛋白质样品在热变性峰之前

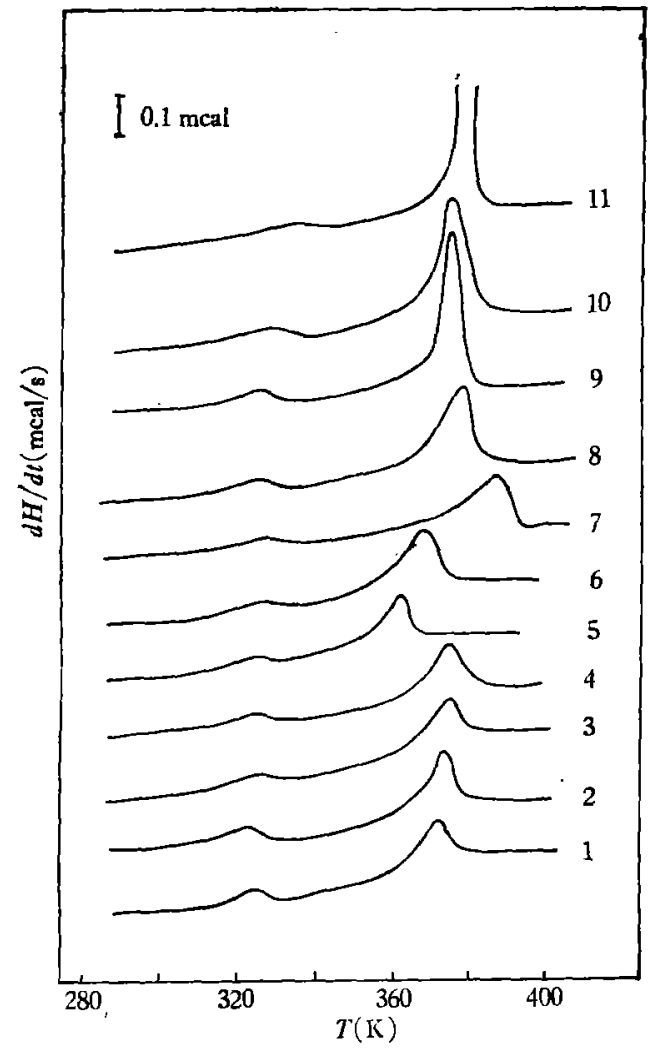

图 111 种蛋白质样品的 DSC 加热扫描曲线 的低温区 $\left(325.0^{\circ} \mathrm{K}-333.6^{\circ} \mathrm{K}\right)$ 内无一例外都 存在一个明显的小吸热峰 $\left(\triangle H_{P D}\right.$ 为 $0.24-$ $0.61 \mathrm{cal} / \mathrm{g}$ ). 从图 2 的曲线 1 和曲线 3 中,可以 看到，在低温区都没有吸热峰存在。空盘扫描 基线 (曲线 1) 为一条直线. 对样品的第二次扫 描曲线 (曲线 3) 既没有变性峰存在也没有低温 区小吸热峰存在,整个曲线只有小的比热变化. 因此曲线 2 中低温区小吸热峰的出现和高温区 变性峰的出现一样是测试样品本身所固有的特 性. 我们将低温区出现的小吸热峰命名为“热

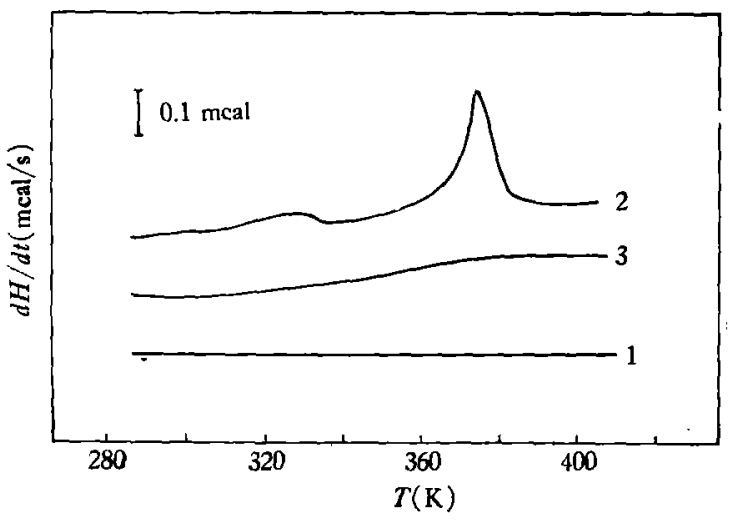

图 2 前后两次连续测试样品的 DSC 扣热扫描曲线 (1.空桖基线，2.样品扫描曲线，3.样品第二次扫描曲线）

变性前新峰”。我们还做了各种条件实验证明新峰的出现与扫描的起始温度及样品的制备方

表 2 样品的状态参数及 DSC 测量结果

\begin{tabular}{|c|c|c|c|c|c|c|c|c|c|}
\hline \multirow[b]{2}{*}{ 序号 } & \multirow[b]{2}{*}{ 样品名称 } & \multirow[b]{2}{*}{ 分子量 } & \multicolumn{3}{|c|}{ 样 品 参 数 } & \multicolumn{3}{|c|}{ 热变性前新峰 } & \multirow{2}{*}{$\begin{array}{l}\text { 变性峰温 } \\
T_{D}\left({ }^{\circ} \mathrm{K}\right)\end{array}$} \\
\hline & & & $\begin{array}{l}\text { 水重 } \\
(\mathrm{m} g)\end{array}$ & $\begin{array}{c}\text { 千重 } \\
(\mathbf{m g})\end{array}$ & $\begin{array}{c}\text { 水合值 } R \\
(\mathrm{~g} \text { 水 } / g \text { 干重 }\end{array}$ & $\begin{array}{l}T_{P D} \\
\left({ }^{\circ} \mathrm{K}\right)\end{array}$ & $\begin{array}{l}\Delta M_{P D} \\
(\mathrm{col} / \mathrm{g})\end{array}$ & $\mid \begin{array}{c}\Delta H_{P D} \\
(\mathrm{kcal} / \mathrm{mol})\end{array}$ & \\
\hline 1 & 牛血清白蛋白 & 67000 & 1.33 & 8.80 & 0.15 & 326.0 & 0.59 & 39.60 & 375.2 \\
\hline 2 & 牛血清白蛋白 & 67000 & 1.33 & 8.76 & 0.15 & 325.0 & 0.59 & 39.53 & 375.0 \\
\hline 3 & 牛血清白蛋白 & 67000 & 1.32 & 8.94 & 0.15 & 327.5 & 0.43 & 28.81 & 377.0 \\
\hline 4 & 牛血清白晸白 & 67000 & 1.28 & 9.26 & 0.14 & 328.1 & 0.50 & 33.50 & 378.6 \\
\hline 5 & 肌 红 蛋 白 & 17600 & 1.21 & 8.12 & 0.15 & 325.3 & 0.61 & 10.74 & 364.0 \\
\hline 6 & 费㠜乳蛋白酶 & 25200 & 1.12 & 8.71 & 0.13 & 328.3 & 0.41 & 10.33 & 371.0 \\
\hline 7 & 刀豆球蛋白 $\mathrm{A}$ & 25500 & 1.23 & 7.97 & 0.15 & 327.0 & 0.24 & 6.12 & 389.0 \\
\hline 8 & 溶 菌 酩 & 14300 & 1.41 & 9.31 & 0.15 & 327.2 & 0.44 & 6.29 & 379.0 \\
\hline 9 & 溶 菌 酶 & 14300 & 1.32 & 9.05 & 0.15 & 325.2 & 0.47 & 6.70 & 377.2 \\
\hline 10 & 核糖核酸酶 & 14000 & 1.21 & 8.75 & 0.14 & 329.2 & 0.55 & 7.70 & 376.7 \\
\hline 11 & 胶 原 蛋 白 & 91/残基 & 1.27 & 6.06 & 0.21 & 333.6 & 0.36 & - & 383.7 \\
\hline
\end{tabular}


法无关. 扫描的起始温度为 $280^{\circ} \mathrm{K}-300^{\circ} \mathrm{K}$, 样品制备采取压片法 (本实验制样法)或采取稍加 压紧的粉末样品,测量结果完全一致,它们的 DSC 加热曲线中都有变性前新峰出现.

本文所用的 7 种蛋白质不仅有球蛋白也有纤维蛋白. 这些蛋白质的氨基酸残基数, 它们 的一级、二级及更高级结构也各不相同。由此我们可以确认“热变性前新峰”的出现是低水含 量蛋白质的共性.

我们认为许多关于水合对蛋白质热变性影响的研究工作, 由于扫描的起始温度已经超过 了新峰的峰温 ${ }^{[13-16]}$, 或者所使用的样品量较少、仪器灵敏度较低, 因此他们未能记录到热变性 前低温区的小吸热峰(新峰).

我们通过进一步的研究已经看到：蛋白质的热变性前新峰只在一定的水合值范围内出 现; 新峰的峰温和焓变值不仅与蛋白质的种类有关,也与水合值密切相关;热谱图中的新峰面积 的大小是蛋白质种类、样品重量及其水合值的函数. 因此可以认为,热变性前新峰的出现是蛋 白质和水相互作用的结果，反映了蛋白质在具不同的水合值时，具有不同的宏观热力学状态. 欲搞清新峰出现的规律及其机制, 必须使用多种技术手段进行综合性研究. 我们相信对热变 性前新峰的出现规律与水合作用的内在关系及其机制的揭示则将会有助于人们深人理解蛋白 质的变性过程、肽链的折叠途径、分子的缔合、解缔合及其溶剂效应.

\section{参考文献}

[1] Bull, H. B., J. Am. Chem. Soc., 66(1944), 1499.

[ 2 ] Reyerson, L. H. and Hnojewyi, W. S., J. Phys. Chem., 64 (1960), 811.

[ 3 ] Rüegg, M. and Hani, H., Biochim. Biophys. Acta., 400(1975), 17.

[ 4 ] Packer, K. J., Phil. Trans. Roy. Soc., B278 (1977), 29.

[ 5 ] Brey, W. S. Jr. et al., J. Colloid. Interface Sci., 26 (1968), 306.

[ 6 ] Cooke, R. and Kuntz, I. D., Ann. Rev. Biophys. Bioeng., 3 (1974), 95.

[ 7 ] Bryant, R. G., Shirley, W. M., in Water in Poly mers (Ed. Rowland, F.), Amer. Chem. Soc., Washing ton DC, 1980.

[ 8 ] Cavatorta, F. et al., J. Chem. Phy., 65(1976), 3635.

[ 9 ] Samanta, S. R. and Walrafen, G. E., ibid., 68(1978), 3313.

[10] Harvey, S. C. and Hoekstra, P., J. Phys. Chem., 76 (1972), 2967.

[11] Schwan, H. P., Ann. N. Y. Acad. Sci., 125(1965), 344.

[12] Grigera, J. R. et al., Biopolymers, 18 (1979), 35.

[13] Fujita, Y. and Noda, Y., Bull. Chem. Soc. Japan., 50(1978), 5.

[14] _ Int. J. Peptide Protein Res., 18(1981), 12-17.

Bull. Chem. Soc. Japan., 54(1981), 3233.

[16] Rüegg, M. et al., Biochimica et Biophysica Acta, 400(1975), 334-342.

[17] Rüegg, M. et al., in Application of Calorimetry in Life (Eds. Lamprecht, I. and Schaarschmidt, B.), 1977.

[18] 章正廉等,生物化学与生物物理学报, 16(1984), 2: 134-139.

[19] 傅亚珍、章正廉,生物化学与生物物理学报, 16(1984), 2: 140-146. 